www.jmscr.igmpublication.org

Impact Factor 5.244

Index Copernicus Value: 83.27

ISSN (e)-2347-176x ISSN (p) 2455-0450

crossref DOI: _http://dx.doi.org/10.18535/jmscr/v4i9.62

Journal Of Medical Science And Clinical Research

\title{
Postoperative Wound Infection in Peptic and Enteric Perforation and Role of Antibiotics: A Prospective Study
}

\author{
Authors \\ Dr Dharmraj Meena ${ }^{1}$, Dr R.S. Meena ${ }^{2}$ \\ ${ }^{2}$ Assistant Professor, ${ }^{1}$ Sr. Professor \\ Department of General Surgery, Govt. Medical College Kota (Rajasthan) India
}

\begin{abstract}
Wound infection continues to be a challenging problem and represents a considerable healthcare burden. A study was conducted in Government Medical College Kota (Rajasthan) to study the incidences of wound infection in perforation cases. Total 100 patients of Peptic and Enteric perforation were included in this study. In this study incidence of wound sepsis in peptic perforation was $16.12 \%$ and in Enteric perforation was $31.57 \%$. E.coli was found responsible in $68 \%$ of cases and Staph. Aureus was found in 18\% of cases while Klebsiella sp. was identified in 14\% of cases. When peritoneal lavage has been done by local antibiotics plus normal saline, wound sepsis was present in $15 \%$ of cases compared to $40 \%$ of with normal saline plus Povidone iodine and $20 \%$ of cases with normal saline alone. Piperacillin-Tazobactam is sensitive in $86.36 \%$ of wound sepsis cases whereas Aminoglycosides were found sensitive in $45.45 \%$ and Fluroquinololes were found sensitive in $31.81 \%$ of cases.
\end{abstract}

Keywords: Peptic, Enteric, Wound infection.

\section{Introduction}

Wound sepsis has been one of the most challenging problems confronting the surgeons. At the minimum, they lead to inconvenience to the patients and the surgeon and at the worst, they cause death. Infections might cause an increase stay in hospital, create discomfort, cause disfigurement and lead to failure of operation. The burden of high rates of surgical wound infections in terms of economics alone is tremendous. These infection poses financial drain on the limited resources available in the hospital in the form of increase in the hospital stay and increase in the need of intensive nursing care for frequent change of sterile dressing and increase duration and dosage of medication that need to be administered. It also increases the total cost of the treatment and suffering of patients.

\section{Aims and Objectives}

1. To determine the incidences of wound infection in both peptic and enteric perforation.

2. To study the effect of different solution for peritoneal lavage during surgery.

3. To determine the bacterial flora responsible for wound infection by culture and sensitivity.

4. To determine the role of antibiotics in addressing wound infection in peptic and enteric perforation peritonitis. 


\section{MATERIAL AND METHODS}

A study was conducted on 100 patients of any age group and both sexes who presented with perforation peritonitis in department of General Surgery MBS Hospital, Govt. Medical College, Kota and were operated upon as a part of management were included.

\section{Inclusion Criteria:}

1. All patients of peptic and enteric perforation of all ages and sex were included study.

\section{Exclusion Criteria:}

1. Patients of traumatic intestinal perforation were excluded from the study.

2. Patients with perforation due to Tuberculosis, inflammatory bowel disease or neoplastic disease were excluded from the study.

3. Esophageal perforation.

4. Caustic injuries.

5. Iatrogenic.

6. Tertiary peritonitis.

7. Primary peritonitis.

Diagnosis was arrived at by thorough history taking and systemic physical examination, assisted by other required basic radiological investigations including X-ray chest PA view, Xray FPA in erect position and USG Abdomen and pelvis.

After preoperative clinical diagnosis, patients were operated as emergency procedure and repair of perforation done according to pathology. Any tissue material if needed was sent for histopathological examination. Peritoneal lavage was done with Normal Saline (NS), or NS with Povidone iodine (PI) or NS with local antibiotics including Ofloxacin and/or Metronidazole.

Patients who developed wound infection were identified and their discharge from wound was sent for culture and sensitivity on $3^{\text {rd }}$ or subsequent post operative day and was treated accordingly.

\section{REVIEW OF LITERATURE}

The whole era of wound asepsis and sterilization revolutionized with the use of carbolic acid to sterilize the wound by Joseph lister ${ }^{1}$. Most SSIs are contaminated by the patient's own endogenous flora, which are present on the skin, mucous membranes, or hollow viscera. The traditional microbial concentration quoted as being highly associated with SSIs is that of bacterial counts higher than 10,000 organisms per gram of tissue (or in the case of burned sites, organisms per $\mathrm{cm}^{2}$ of wound ${ }^{2}$

Most SSIs are contaminated by the patient's own endogenous flora, which are present on the skin, mucous membranes, or hollow viscera. The traditional microbial concentration quoted as being highly associated with SSIs is that of bacterial counts higher than 10,000 organisms per gram of tissue (or in the case of burned sites, organisms per $\mathrm{cm}^{2}$ of wound ${ }^{[3,4]}$.

The high rate of wound sepsis in enteric perforation was mainly due to faecal contamination of peritoneal cavity. This is also shown by the study done by Khanna AK 1984 done on perforation peritonitis ${ }^{[46]}$.

Brian McCluskey stated in his study, ${ }^{[54]} a$ prospective trial of Povidone iodine solution in the prevention of wound sepsis, that instillation of Povidone iodine (PVI) solution into to peritoneal cavity for irrigation wound failed to reduce the incidence of wound sepsis. The rate of wound sepsis is similar or higher to condition when wound cavity was washed with normal saline solution.

Effect of peritoneal irrigation by antibiotic solution on wound sepsis was also exemplified by

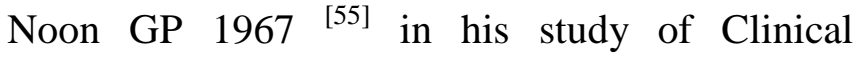
evaluation of peritoneal irrigation with antibiotic solution. He found that wound sepsis is comparatively lesser when peritoneal lavage was done by antibiotic solution. 


\section{RESULTS}

Table-1 Number of Patients With Wound Sepsis In Relation To Perforation

\begin{tabular}{|l|l|l|l|}
\hline $\begin{array}{l}\text { Type Of } \\
\text { Perforation }\end{array}$ & $\begin{array}{l}\text { Number Of } \\
\text { Infected Cases }\end{array}$ & $\begin{array}{l}\text { Total } \\
\text { Cases }\end{array}$ & Percentage \\
\hline Peptic & 10 & 62 & $16.12 \%$ \\
\hline Enteric & 12 & 38 & $31.57 \%$ \\
\hline
\end{tabular}

In this study, incidence of wound sepsis in peptic perforation was $16.12 \%$ and in enteric perforation was $31.57 \%$.

Table-2 Nubmer of Wound Sepsis Cases In Relation to Peritoneal Lavage Solution

\begin{tabular}{|l|l|l|l|}
\hline Solution & $\begin{array}{l}\text { No, of } \\
\text { septic } \\
\text { cases }\end{array}$ & $\begin{array}{l}\text { No. of } \\
\text { total } \\
\text { cases }\end{array}$ & Percentage \\
\hline Normal Saline & 13 & 65 & $20 \%$ \\
\hline $\begin{array}{l}\text { Normal } \\
\text { Saline+Povidone } \\
\text { Iodine }\end{array}$ & 06 & 15 & $40 \%$ \\
\hline $\begin{array}{l}\text { Normal Saline+Local } \\
\text { antibiotics }\end{array}$ & 03 & 20 & $15 \%$ \\
\hline
\end{tabular}

In this study, incidences of wound sepsis cases was less when peritoneal lavage been done with local antibiotics $(15 \%)$

Incidences of wound sepsis were higher in patients when peritoneal lavage done with normal saline with Povidone iodine (40\%) compared to $20 \%$ when only normal saline was used for peritoneal lavage.

Table-3 Number of Wound Sepsis Cases In Relation Of Post Operative Days

\begin{tabular}{|l|l|l|}
\hline $\begin{array}{l}\text { Day of detection } \\
\text { of wound sepsis }\end{array}$ & $\begin{array}{l}\text { No. of sepsis } \\
\text { cases }\end{array}$ & Percentage \\
\hline Day 1 & 0 & 0 \\
\hline Day 2 & 1 & $4.54 \%$ \\
\hline Day 3 & 9 & $40.90 \%$ \\
\hline Day 4 & 3 & $13.63 \%$ \\
\hline Day 5 & 7 & $31.82 \%$ \\
\hline Day 6 & 2 & $9.09 \%$ \\
\hline
\end{tabular}

In this study, maximum no. of sepsis cases were detected on day $3^{\text {rd }}(40.90 \%)$ followed by $31.82 \%$ on day $5^{\text {th }}$.

Table-4 Organism Cultured From Discharge

\begin{tabular}{|l|l|l|}
\hline Organism & $\begin{array}{l}\text { Number Of } \\
\text { Cases }\end{array}$ & Percentage \\
\hline E.Coli & 15 & $68.18 \%$ \\
\hline Staph. Aureus & 4 & $18.18 \%$ \\
\hline Klebsiella Sp. & 3 & $13.64 \%$ \\
\hline
\end{tabular}

In this study, E.coli was found as a cause of wound sepsis on culture and sensitivity in $68.18 \%$ of cases while Staph. aureus and Klebsiella sp. Were responsible for wound sepsis in $18.18 \%$ and $13.64 \%$ of cases.

Table-5 Pattern of Antibiotic Sensitivity

\begin{tabular}{|l|l|l|}
\hline Antibiotics & $\begin{array}{l}\text { Number Of Sensitive } \\
\text { Patients }\end{array}$ & Percentage \\
\hline $\begin{array}{l}\text { Piperracillin+ } \\
\text { Tazobactam }\end{array}$ & 19 & $86.36 \%$ \\
\hline Aminoglycoside & 10 & $45.45 \%$ \\
\hline Ofloxacin & 7 & $31.82 \%$ \\
\hline Other & 3 & 13.63 \\
\hline
\end{tabular}

In this study, $86.36 \%$ cases of wound sepsis were sensitive to Piperacillin+Tazobactam. Aminogycosides were found sensitive in $45.45 \%$ of cases and Ofloxacin was found sensitive in $31.82 \%$ of cases. $13.63 \%$ cases of wound sepsis were sensitive to other antibiotics like Linezolid and Rifampicin.

\section{DISCUSSION}

In this study, Wound sepsis was found in $16.12 \%$ casesof peptic perforation as compared to $31.57 \%$ in cases of enteric perforation. This high rate of wound sepsis in enteric perforation was mainly due to faecal contamination of peritoneal cavity and poor general condition of the patient at the time of surgery. This is also shown by the study done by Khanna AK 1984 done on perforation peritonitis 5 .

In this present study, rate of wound sepsis was also measured according to type of laparotomy incisions used in this study while operating the patients.

Two type of incisions were used-Midline and Right paramedian. Wound sepsis developed in 5 out of 2 cases $(17.85 \%)$ of Right paramedian incision while would sepsis occurred in 17 out of 72 cases $(23.61 \%)$ when midline incision was used. This difference was not statistically significant. Burger et al. (Burger 2002) ${ }^{8}$ published a systemic review of prospective randomized trials of abdominal incision types and complications. In this review transverse, oblique, 
paramedian and midline incisions were included. They reported an increased rate of incisional hernia with a midline incision, but no differences in infection and dehiscence rates compared with any other incision. This increased incisional hernia rate was only sustained in the group of patients undergoing what they defined as "larger laparotomies". They concluded that the use of the midline incision should be restricted to operations in which unlimited access to the abdominal cavity is useful or necessary, recommending instead the paramedian incision.

Wound dehiscence was found in $22.72 \%$ cases in this study which is also shown by study done by Khanna $\mathrm{AK}^{5}$ et al on their study on perforation peritonitis.

In this study and association of wound sepsis was identified when different solutions were used for peritoneal irrigation. When peritoneal lavage had been done with normal saline wound sepsis was seen in $20 \%$ of cases. Incidences wound sepsis was $40 \%$ when peritoneal irrigation was done with Povidone iodine coupled with normal saline as it is shown by Brian McCluskey ${ }^{6}$ in his study.

When peritoneal cavity had been washed with antibiotic solution and normal saline, wound sepsis was seen in $14 \%$ of cases. Similar results were also suggested by Noon $\mathrm{GP}^{7}$ in his study.

As in these studies, the results from the present study also show a significant relationship between extreme of age. The lowest risk of developing wound sepsis was seen in the age group of 31-40 years (10\%), probably this age group had patients who were relatively in the prime of their health. The rate of postoperative wound sepsis shows a rising trends of either side of this age group peaking at $100 \%$ at $71-81$ years age group followed by $45.45 \%$ at $61-70$ years. On studying the rate of wound sepsis across the various age groups, our findings are similar to other international studies. (Howard 19649\% Davidson $1971^{10}$ Maed, 1986 ${ }^{11}$; Cleasson and Holmlund, $1988^{12}$.

Analysis of wound discharge by culture and sensitivity shows that E.coli was the most common organism grown on culture and sensitivity, seen in $68 \%$ fo patients followed by Staph. aureus in 18 of cases. Klebsiella sp. was grown in $14 \%$ of isolates.

Emori $\mathrm{TG}^{13}$ studied that the clinical significance of bacterial translocation remains unclear although there is increasing circumstantial evidence to suggest that it may play an important role in the causation of sepsis. For example, it is well recognized that nosocomial infection is frequently a consequence of gut derived organism, such as Escherichia coli.

In this study detection of wound sepsis was maximum on $3^{\text {rd }}$ postoperative day $(40.90 \%)$ followed by on $5^{\text {th }}$ postoperative day $(31.82 \%)$. Nicholas (1996) ${ }^{[14]}$ reported similar results with maximum incidence between fourth and eighth postoperative day. This is because microorganism inoculated in the wound at the time of surgery need 72 hours or more multiply and to produce clinical signs and symptoms.

Pain at the surgical site infection was the most common clinical symptom of postoperative wound infection being found in $77.38 \%$ of patients. This is slightly lower than $88.3 \%$ as reported by Nichols (1996) ${ }^{[14]}$ but this difference does not reaches statistically significant value.

Discharge from wound site (serous, Serosanguinous, purulent) was found in all patients and it is the most common sign recorded.

We observed that serous discharge was found in $18.18 \%$ of cases while Serosanguinous discharge was seen in $31.82 \%$ of cases. Purulent discharge was seen in maximum number of cases $(50 \%)$.

We observed that during this study systemic sign as fever as an indicator of wound sepsis were not present in isolation without any evidence of infection. Fever was seen in $36.36 \%$ of cases.

On antibiotic sensitivity testing it found that Piperacillin+Tazobactam was sensitive in $86.36 \%$ of clinical specimens. Aminogycosides antibiotics were found sensitive in $45.45 \%$ of cases while Fluoroquinolones was sensitive in $31.82 \%$ of patients. Only 3 out of 22 cases (13.63\%) were 
found sensitive to other antibiotics like Linezolid and Rifampicin.

\section{CONCLUSION}

The development of postoperative wound sepsis is an important event that cannot always be prevented. It can, however, be minimized by careful, exacting surgical technique, judicious use of proper antibiotics, early aggressive and judicious surgical procedure, thorough abdominal toileting and strict asepsis.

\section{REFERENCES}

1. Lister J. On a new method of treating compound fractures. Lancet. 1867;1:326329,387-389,507-509.

2. Krizek TJ, Robson MC. Evolution of quantitative bacteriology in wound management. Am J Surg. Nov 1975;130(5):579-84.

3. Margiotta SJ, Horwitz JR, Willis IH, Wallack MK. Cholecystectomy in the elderly. Am. J Surg 1988; 156:509-12.

4. Thompson Je, Tompkins RK Longmire WP. Factors in Management of acute cholangitis. Ann Surg 1982 ; 195:137-45. 